\title{
Cardio-ankle vascular index is associated with cardiovascular target organ damage and vascular structure and function in patients with diabetes or metabolic syndrome, LOD-DIABETES study: a case series report
}

Manuel Ángel Gómez-Marcos ${ }^{1,2 *}$, José Ignacio Recio-Rodríguez ${ }^{1}$, María Carmen Patino-Alonso 1,3,

Cristina Agudo-Conde1, Leticia Gómez-Sánchez ${ }^{1}$, Marta Gomez-Sanchez ${ }^{1}$, Emiliano Rodríguez-Sanchez ${ }^{1,2}$, Jose Angel Maderuelo-Fernandez ${ }^{1}$, Luís García-Ortiz ${ }^{1,2}$ and LOD-DIABETES Group

\begin{abstract}
Background: The cardio ankle vascular index (CAVI) is a new index of the overall stiffness of the artery from the origin of the aorta to the ankle. This index can estimate the risk of atherosclerosis. We aimed to find the relationship between CAVI and target organ damage (TOD), vascular structure and function, and cardiovascular risk factors in Caucasian patients with type 2 diabetes mellitus or metabolic syndrome.
\end{abstract}

Methods: We included 110 subjects from the LOD-Diabetes study, whose mean age was $61 \pm 11$ years, and 37.3\% were women. Measurements of CAVI, brachial ankle pulse wave velocity (ba-PWV), and ankle brachial index (ABI) were taken using the VaSera device. Cardiovascular risk factors, renal function by creatinine, glomerular filtration rate, and albumin creatinine index were also obtained, as well as cardiac TOD with ECG and vascular TOD and carotid intima media thickness (IMT), carotid femoral PWV (cf-PWV), and the central and peripheral augmentation index (CAlx and PAIx). The Framingham-D'Agostino scale was used to measure cardiovascular risk.

Results: Mean CAVI was $8.7 \pm 1.3$. More than half (54\%) of the participants showed one or more TOD (10\% cardiac, $13 \%$ renal; 48\% vascular), and 13\% had ba-PWV $\geq 17.5 \mathrm{~m} / \mathrm{s}$. Patients with any TOD had the highest CAVI values: 1.15 (CI 95\% 0.70 to $1.61, \mathrm{p}<0.001)$ and 1.14 (Cl 95\% 0.68 to $1.60, \mathrm{p}<0.001$ ) when vascular TOD was presented, and 1.30 (Cl 95\% 0.51 to $2.10, p=0.002$ ) for the cardiac TOD. The CAVI values had a positive correlation with HbA1c and systolic and diastolic blood pressure, and a negative correlation with waist circumference and body mass index. The positive correlations of CAVI with IMT ( $\beta=0.29 ; p<0.01)$, cf-PWV $(\beta=0.83 ; p<0.01)$, ba-PWV $(\beta=2.12 ; p<0.01), C A l x(\beta=3.42$; $p<0.01)$, and PAlx $(\beta=5.05 ; p=0.04)$ remained after adjustment for cardiovascular risk, body mass index, and antihypertensive, lipid-lowering, and antidiabetic drugs.

Conclusions: The results of this study suggest that the CAVI is positively associated with IMT, Cf-PWV, ba-PWV, CAlx, and PAIx, regardless of cardiovascular risk and the drug treatment used. Patients with cardiovascular TOD have higher values of CAVI.

(Continued on next page)

\footnotetext{
* Correspondence: magomez@usal.es

${ }^{1}$ Primary Care Research Unit, the Alamedilla Health Center, Avda. Comuneros 27, 37003 Salamanca, Spain

${ }^{2}$ Medicine Department, University of Salamanca, Salamanca, Spain

Full list of author information is available at the end of the article
} 
(Continued from previous page)
Trial registration: Clinical Trials.gov Identifier: NCT01065155

Keywords: Target organ damage, Cardio ankle vascular index, Vascular structure, Vascular function, Cardiovascular risk, Diabetes mellitus type 2, Metabolic syndrome

\section{Background}

The early detection of atherosclerosis is important for patients with type 2 diabetes mellitus (T2DM) or metabolic syndrome [1], because cardiovascular disease is a main cause of death in these people [2,3]. These pathologies are associated with more cardiovascular risk factors [4,5], more comorbidities [6,7], and more renal [8], cardiac $[9,10]$, and vascular $[11]$ target organ damage (TOD). They are also associated with premature vascular aging and altered parameters assessing vascular structure, such as the ankle brachial index (ABI) [12] or carotid intima media thickness (IMT) [11]. They also occur with increased arterial stiffness [13] based on carotid femoral pulse wave velocity (cf-PWV), or with high brachialankle pulse wave velocity (ba-PWV) could predict all-cause mortality and cardiovascular events in subjects with diabetes $[14,15]$, increased ba-PWV was significantly correlated with cardiac autonomic neuropathy and with subclinical myocardial injury in patients with type 2 diabetes [16].They are also associated with pulse wave parameters such as the central and peripheral augmentation indices (CAIX and PAIx) [17-19].

The cardio-ankle vascular index (CAVI) is a new index $[20,21]$ of the overall stiffness of the artery from the origin of the aorta to the ankle, and it is able to estimate the risk of atherosclerosis [22]. The arterial stiffness estimated using CAVI in healthy subjects increases linearly with aging, and is higher in men than in women [23]. In patients with risk factors such as diabetes or obesity [24-26], the CAVI values are higher than in controls. CAVI is associated with carotid and coronary atherosclerosis [27-29]. The CAVI method is a useful tool to screen people with moderate to advanced levels of atherosclerosis [30].

Even though there is much evidence supporting the relationship between CAVI and cardiovascular risk factors and atherosclerosis, most studies have been done on Asian populations. The clinical relevance of this work is given because it is the first study to analyze in the same sample, the association between CAVI and cardiovascular risk factors, TOD (renal, vascular, and heart), other parameters of vascular structure and function, and the thickness of the retinal vessels in Caucasian patients with increased insulin resistance. Therefore, the aim of this study is to analyze the association of CAVI with target organ damage, vascular structure and function, and cardiovascular risk factors in Caucasian patients with T2DM or metabolic syndrome.

\section{Methods}

Study design

This study analyzed 110 subjects in the 4th year of follow up who were included in the longitudinal LODDIABETES study (NCT01065155) [31].

\section{Study population}

Using consecutive sampling, we included 112 patients who visited their family doctor from January 2009 to January 2010 with T2DM $(n=68)$, which was defined using the American Diabetes Association criteria [32] or metabolic syndrome $(\mathrm{n}=44)$ (defined according to the National Cholesterol Education Program, ATP III1 definition [33]). The subjects were sampled from a population of 46000 people from two primary care centers (including 2412 diagnosed with diabetes and 4100 with metabolic syndrome). The exclusion criteria were patients unable to comply with the protocol requirements (psychological and/or cognitive disorders, failure to cooperate, educational limitations, problems with understanding written language, failure to sign the informed consent document), patients participating or planning to participate in a clinical trial during the study, and patients with serious comorbidities representing a threat to life over the subsequent 12 months. Patients with a history of cardiovascular disease were not excluded from the study. A sample-size calculation indicated that the 110 patients included in the study constituted a sufficient sample for detecting a correlation coefficient of 0.26 between CAVI and IMT in a two-sided test, with a significance level of $95 \%$ and power of $80 \%$ (EPIDAT 4.0). The study was approved by an independent ethics committee of Salamanca University Hospital (Spain), and all participants gave written informed consent according to the general recommendations of the Declaration of Helsinki [34].

\section{Measurements}

A detailed description has been published elsewhere regarding how the clinical data were collected, the anthropometric measurements were made, blood pressure was recorded, TOD was assessed, and the analytical parameters were obtained [31].

\section{Office blood pressure}

Office blood pressure (BP) was calculated as the average of the last two of three measurements of systolic blood 
pressure (SBP) and diastolic blood pressure (DBP) made with a validated sphygmomanometer (OMRON Model M10-IT). Measurements were made on the dominant arm of participants in the seated position after at least 5 minutes of rest, with a cuff of appropriate size as determined by measurement of the upper-arm circumference and following the recommendations of the European Society of Hypertension [35].

\section{Vascular assessment}

Cardio ankle vascular index (CAVI), brachial ankle pulse wave velocity (ba-PWV), and ankle/brachial index (ABI) were measured using a VaSera VS- $1500^{\circ}$ device (Fukuda Denshi). The ba-PWV was calculated, as was CAVI, which gives a more accurate calculation of the degree of atherosclerosis. CAVI integrates the cardiovascular elasticity derived from the aorta to the ankle pulse velocity through an oscillometric method, it is used as a good measure of vascular stiffness, and it does not depend on BP [21]. CAVI values were automatically calculated by substituting the stiffness parameter $\beta$ in the following equation to detect the vascular elasticity and the brachial ankle PWV: Stiffness parameter $\beta=2 \rho \times 1 /(\mathrm{Ps}-\mathrm{Pd}) \times \ln (\mathrm{Ps} / \mathrm{Pd}) \times$ ba-PWV ${ }^{2}$, where $\rho$ is the blood density, Ps and Pd are SBP and DBP in $\mathrm{mmHg}$, respectively, and the ba-PWV is measured between the aortic valve and the ankle. The average coefficient of the variation of the CAVI is less than $5 \%$, which is small enough for clinical use and confirms that CAVI has favorable reproducibility $[20,23]$. CAVI was measured at rest and considered normal $(\mathrm{CAVI}<8)$, borderline $(8 \leq \mathrm{CAVI}<9)$, or abnormal with subclinical atherosclerosis (CAVI $\geq 9$ ). ba-PWV $\geq 17.5$ was considered abnormal [36,37]. The higher obtained CAVIs and ba-PWV were considered for the study.

\section{Carotid femoral pulse wave velocity (cf-PWV) and peripheral (PAIx) and central augmentation index (CAIx)}

These parameters were estimated using the SphygmoCor System (AtCor Medica lPty Ltd., Head Office, West Ryde, Australia). The central augmentation index (CAIx) is a composite index that integrates the amount of the wave that is reflected back to the aorta depending on the tone of the resistance arteries, which are the main peripheral reflecting sites. This system (Px Pulse Wave Analysis) was used with the patient in the sitting position and resting the arm on a rigid surface. Pulse wave analysis was performed with a sensor in the radial artery using mathematical transformation to estimate the aortic pulse wave. The reliability of these measurements was evaluated before the study using the CAIx intra-class correlation coefficient (ICC), which showed values of 0.97 (95\% CI: 0.94-0.99) for intra-observer agreement in repeated measurements of 22 subjects. According to the Bland-Altman analysis, the mean difference for intraobserver agreement (95\% limits of agreement) was 0.45 (-9.88-10.79). From the morphology of the aortic wave, CAIx was estimated using the following formula: increase in central pressure $\times 100$ / pulse pressure. The value was adjusted to a heart rate of 75 by the SphygmoCor System device.

The peripheral augmentation index (PAIx) is a measurement taken directly from the late systolic shoulder of the peripheral arterial waveform. The index is defined as the ratio of the difference in amplitude between the second peak and diastolic pressure to the difference between the first peak and diastolic pressure [18]. The PAIx was calculated to yield a percent (\%) value as follows: (second peak systolic blood pressure [SBP2] - diastolic blood pressure $[\mathrm{DBP}]) /($ first peak SBP $-\mathrm{DBP}) \times 100$ [18]. The pulse waves of the carotid and femoral arteries were analyzed using the SphygmoCor System with the patient in a supine position. The delay was estimated with respect to the ECG wave and calculating PWV. Distance measurements were taken with a measuring tape from the sternal notch to the carotid and femoral arteries at the sensor location [35]. Subclinical organ damage was defined as cf-PWV $>12 \mathrm{~m} / \mathrm{s}$ [35].

\section{Assessment of vascular structure by carotid intima media thickness (IMT)}

Carotid ultrasound to assess carotid IMT was performed by two investigators trained for this purpose before starting the study. The reliability of the recordings was evaluated before the study using the intra-class correlation coefficient, which showed values of 0.97 (95\% CI: 0.94 to 0.99 ) for intra-observer agreement in repeated measurements on 20 subjects, and 0.90 (95\% CI: 0.74 to 0.96 ) for interobserver agreement. According to the Bland-Altman analysis, the mean difference for interobserver agreement (95\% limits of agreement) was 0.01 ( -0.03 to 0.06). A Sonosite Micromax ultrasound device paired with a 5-10 MHz multi-frequency high-resolution linear transducer with Sonocal software was used for performing automatic measurements of IMT in order to optimize reproducibility.

Measurements were made of the common carotid after the examination of a $10-\mathrm{mm}$ longitudinal section at a distance of $1 \mathrm{~cm}$ from the bifurcation. They were performed in the anterior or proximal wall and in the posterior or distal wall in the lateral, anterior, and posterior projections. The measurements were taken following an axis perpendicular to the artery to discriminate two lines: one for the intima-blood interface and the other for the media-adventitious interface. A total of 6 measurements were obtained of the right carotid, with another 6 measurements of the left carotid. Average values (average IMT) automatically calculated by the software were used [38]. The measurements were 
obtained with the subject lying down, with the head extended and slightly turned opposite to the examined carotid artery. Average IMT was considered abnormal if $>0.90 \mathrm{~mm}$, if there were atherosclerotic plaques with a diameter of $1.5 \mathrm{~mm}$, or if there was a focal increase of $0.5 \mathrm{~mm}$ or $50 \%$ of the adjacent IMT [35].

\section{Evaluation of retinal vessels}

Retinography was performed using a Topcon TRC NW 200 non-mydriatic retinal camera (Topcon Europe B.C., Capelle a/d Ijssel, The Netherlands). Nasal and temporal images centered on the disk were obtained. The nasal image with the centered disk was loaded into developed software called the arteriolar-venular (AV) diameters index calculator (Ciclorisk SL, Salamanca, Spain, registry no. 00/2011/589). The software automatically recognizes the disk and draws two external concentric circles which delimit area $\mathrm{A}$, which is between 0 and 0.5 disk diameters from the optic disk margin, and area $B$, which is between 0.5 and 1 disk diameters from the margin.

The software first identifies the limits of the different vessels and then automatically recognizes arteries and veins. Then, it makes multiple measurements of the diameter of the section of the vessels circulating through area B. It finally estimates the mean caliber of veins and arteries in $\mathrm{mm}$, and these measurements are summarized as an arteriole-venule ratio (AVR). An AVR of 1.0 suggests that arteriolar diameters are the same on average as venular diameters in the eye, whereas a smaller AVR suggests narrower arterioles [39].

We used pairs of the main vessels in the upper and lower temporal quadrants, rejecting all other vessels, to improve reliability and increase efficiency of the process. Measures are analyzed for each quadrant separately and together to estimate the mean measure in each eye. The reliability of such recordings was evaluated before the study using the ICC, which showed values of 0.998 (95\% CI: 0.997 to 0.999$)$ for vein caliber, 0.969 (95\% CI 0.940-0.984) for arteries, and 0.981 (95\% CI $0.965-$ 0.990) for AVR intraobserver ICC, which was measured using a subsample of 40 photographs. The estimated average time to analyze a patient (two photographs) was less than $2 \min [40]$.

\section{Renal assessment}

Kidney damage was assessed by measuring plasma creatinine concentration. Glomerular filtration rate (GFR) was estimated according to the Modification of Diet in Renal Disease-Isotopic Dilution Mass Spectrometry (MDRD-IDMS) [41], and proteinuria was assessed from the albumin/creatinine ratio. TOD was defined according to the criteria in the 2007 European Society of Hypertension/European Society of Cardiology Guidelines [42].

\section{Cardiac assessment}

The electrocardiographic examination was performed using a General Electric MAC 3.500 ECG System (General Electric, Niskayuna, NY, USA), which automatically measures the voltage and duration of waves and estimates the criteria of the Sokolow and Cornell voltage-duration product (Cornell VDP). TOD was defined according to criteria in the 2007 European Society of Hypertension/ European Society of Cardiology Guidelines [42].

\section{Cardiovascular risk assessment}

Risk of cardiovascular morbidity and mortality was estimated using the published Framingham-D'Agostino risk equation [43]. Risk factors for morbidity and mortality used by the Framingham-D'Agostino scale include age, total cholesterol, high-density lipoprotein cholesterol, and SBP as quantitative variables. Sex, drug treatment for hypertension, smoking, and history of diabetes mellitus are dichotomous variables. We considered patients to be at high risk when the scale was $\geq 20 \%$ for the next 10 years. The individuals performing the different tests were blinded to the clinical data of the patients. All assessments were made within a period of 10 days.

\section{Statistical analysis}

Continuous variables were expressed as the mean \pm standard deviation for normally distributed continuous data, the median (interquartile range, IQR) for asymmetrically distributed continuous data, and the frequency distribution for categorical data. Statistical normality was tested using the Kolmogorov-Smirnov test. Quantitative variables were compared using the Student t-test or Mann-Whitney U-test as appropriate. A partial correlation was examined between CAVI with cardiovascular risk factors and target organ damage, controlling for age, gender, and antihypertensive, lipid-lowering, and antidiabetic drugs. We performed multiple linear regression analyses with CAVI as the independent variable and IMT mean, CAIx, PAIx, AVR, cf-PWV, and ba-PWV as dependent variables. We adjusted by FraminghamD'Agostino cardiovascular risk, body mass index (BMI), and antihypertensive, lipid-lowering, and antidiabetic drugs. The data were analyzed using the Statistical Package for the Social Sciences version 20.0 (SPSS, Chicago, IL, USA). A value of $\mathrm{p}<0.05$ was considered statistically significant.

\section{Results}

Throughout the fourth year of study of follow-up, two males died as a result of acute myocardial infarction: one with T2DM and the other with metabolic syndrome (aged 76 and 65 years, respectively).

Table 1 shows the demographics and clinical characteristics, cardiovascular risk factors, and cardiovascular 
Table 1 Baseline demographic and clinical characteristics of patients

\begin{tabular}{|c|c|c|}
\hline Variable & $\begin{array}{l}\text { Mean/Median/ } \\
\text { Number } \mathrm{n}\end{array}$ & SD/IQR/ (\%) \\
\hline Age (years) & 61.2 & 11.1 \\
\hline Female sex n (\%) & 41 & 37.3 \\
\hline Smoking n (\%) & 19 & 17.6 \\
\hline Ischemic heart disease n (\%) & 11 & 10 \\
\hline Cerebrovascular disease n (\%) & 3 & 3.9 \\
\hline Waist circumference (cm) & 102.9 & 11.9 \\
\hline Body mass index $\left(\mathrm{kg} / \mathrm{m}^{2}\right)$ & 30.2 & 4.8 \\
\hline Obesity n (\%) & 55 & 50.9 \\
\hline Office systolic blood pressure (mmHg) & 132 & 16 \\
\hline Office diastolic blood pressure (mmHg) & 77 & 10 \\
\hline Office pulse pressure (mmHg) & 56 & 15 \\
\hline Heart rate (beats/min) & 68 & 11 \\
\hline Hypertension n (\%) & 90 & 81.8 \\
\hline Antihypertensive drugs n (\%) & 88 & 81.5 \\
\hline Serum glucose (mg/dL) & 103 & 89.3-128.3 \\
\hline HbA1c (\%) & 6.3 & $5.7-7.0$ \\
\hline Diabetes n (\%) & 71 & 64.5 \\
\hline Antidiabetic drugs n (\%) & 65 & 60.2 \\
\hline Total cholesterol (mg/dL) & 185.3 & 31.9 \\
\hline Triglycerides (mg/dL) & 128 & $95.0-162.5$ \\
\hline $\begin{array}{l}\text { High density lipoprotein } \\
\text { cholesterol (mg/dL) }\end{array}$ & 50.2 & 11.8 \\
\hline $\begin{array}{l}\text { Low density lipoprotein } \\
\text { cholesterol (mg/dL) }\end{array}$ & 109.5 & 29.7 \\
\hline Dyslipidemia n (\%) & 68 & 63.6 \\
\hline Metabolic syndrome n (\%) & 39 & 35.5 \\
\hline Lipid lowering drugs n (\%) & 70 & 64.8 \\
\hline $\begin{array}{l}\text { Cardiovascular risk Framingham } \\
\text { D'Agostino }\end{array}$ & 25.3 & 19.5 \\
\hline
\end{tabular}

Values are means and standard deviations (SD) for normally distributed continuous data, medians and interquartile range (IQR) for asymmetrically distributed continuous data and absolute frequency and proportions for categorical data.

risk estimated with the Framingham-D'Agostino scale. The mean age was $61.2 \pm 11.1$ years (women 50.6 ; men 62.2 ), and $37.3 \%$ of the 110 subjects were women.

Table 2 shows the TOD and the parameters used to assess the vascular structure and function. Among the patients, $54 \%$ had one or more TOD: $10 \%$ cardiac, $13 \%$ renal, and $48 \%$ vascular. $13 \%$ had ba-PWV $\geq 17.5 \mathrm{~m} / \mathrm{s}$. The CAVI value was $8.71 \pm 1.28$ in men and $8.65 \pm 1.40$ in women.

Subjects with CAVI $\geq 9$ were older and had higher values of HbA1c, office systolic blood pressure, cardiovascular risk, IMT, cf-PWV, ba-PWV, and PAIx, and they had lower values of total and LDL cholesterol (Table 3).
Table 2 Values of organ damage markers and vascular structure and function parameters

\begin{tabular}{|c|c|c|}
\hline Variable & $\begin{array}{l}\text { Mean/Median/ } \\
\text { Number } \mathrm{n}\end{array}$ & SD/IQR/ (\%) \\
\hline Serum creatinine (mg/dL) & 0.9 & $0.7-1$ \\
\hline Target organ damage creatinine n (\%) & 4 & 3.7 \\
\hline $\begin{array}{l}\text { GFR with MDRD-IDMS } \\
\left(\mathrm{mL} / \mathrm{min} / 1.73 \mathrm{~m}^{2}\right)\end{array}$ & 89.9 & 19.8 \\
\hline Target organ damage (GFR <60) n (\%) & 6 & 5.6 \\
\hline Albumin/creatinine (mg/g) & 2.58 & $0.0-8.88$ \\
\hline $\begin{array}{l}\text { Target organ damage } \\
\text { (Albumin/creatinine) } \mathrm{n}(\%)\end{array}$ & 10 & 9.3 \\
\hline Target organ damage renal n (\%) & 14 & 13.1 \\
\hline Cornell VDP (mmms) & 1604.1 & 645.3 \\
\hline Sokolow (mm) & 20.1 & 6.4 \\
\hline Target organ damage heart n (\%) & 11 & 10.3 \\
\hline Ankle/brachial index & 1.14 & 0.11 \\
\hline $\begin{array}{l}\text { Target organ damage ankle/ } \\
\text { brachial index } \mathrm{n}(\%)\end{array}$ & 5 & 4.7 \\
\hline $\begin{array}{l}\text { Carotid Intima-media thicknes } \\
\text { average mean }(\mathrm{mm})\end{array}$ & 0.78 & 0.12 \\
\hline Target organ damage Carotid n (\%) & 36 & 33.6 \\
\hline cf-PWV (m/sec) & 9.6 & 2.6 \\
\hline $\begin{array}{l}\text { Target organ damage Pulse } \\
\text { Wave Velocity } n(\%)\end{array}$ & 30 & 28.0 \\
\hline Target organ damage Vascular n (\%) & 51 & 47.7 \\
\hline Target organ damage global & 58 & 54.2 \\
\hline Arteriovenous índex & 0.81 & 0.13 \\
\hline Arteriolar caliber mean $(\mu \mathrm{m})$ & 106.66 & 13.17 \\
\hline Venular caliber mean $(\mu \mathrm{m})$ & 138.55 & 16.80 \\
\hline Central Augmentation Index & 27.09 & 13.21 \\
\hline Peripheral Augmentation index & 90 & $78-102.5$ \\
\hline ba-PWV (m/sec) & 14.76 & 3.09 \\
\hline ba-PWV $\geq 17.5(\mathrm{~m} / \mathrm{sec})$ & 14 & 13.3 \\
\hline Cardio-Ankle Vascular Index. & 8.70 & 1.31 \\
\hline
\end{tabular}

Values are means and standard deviations (SD) for normally distributed continuous data, medians and interquartile range (IQR) for asymmetrically distributed continuous data and absolute frequency and proportions for categorical data.

GFR: Glomerular filtration rate. MDRD-IDMS: Modification of Diet in Renal Disease-Isotopic Dilution Mass Spectrometry. VDP: Voltage-Duration Product. cf-PWV: carotid femoral Pulse Wave Velocity. ba-PWV: brachial ankle Pulse Wave Velocity.

The difference in CAVI between patients with any TOD and patients without TOD was 1.15 (CI 95\% 0.70 to 1.61 , $\mathrm{p}<0.001$ ). This difference was 1.14 (CI95\% 0.68 to 1.60 , $\mathrm{p}<0.001$ ) in vascular TOD, 1.30 (CI 95\% 0.51 to 2.10 , $\mathrm{p}=$ 0.002 ) in the cardiac TOD, and 0.48 (CI 95\% -0.27 to 1.22 , $\mathrm{p}=0.206$ ) in renal TOD (Figure 1 ).

The CAVI has a positive correlation with age $(r=0.647$; $\mathrm{p}<0.01)$. The CAVI values had positive correlations 
Table 3 Values of cardiovascular risk factors, organ damage markers and vascular structure and function parameters according to CAVI value

\begin{tabular}{|c|c|c|c|}
\hline Value of CAVI & CAVI < 9 (58\%) Mean/Median/SD/IQR & CAVI $\geq 9$ (42\%) Mean/Median/SD/IQR & p-value \\
\hline Age (years) & $56.5 \pm 11.4$ & $67.7 \pm 7.3$ & $<0.01$ \\
\hline Waist circumference $(\mathrm{cm})$ & $102.9 \pm 10.7$ & $102.2 \pm 12.6$ & 0.77 \\
\hline Body mass index $(\mathrm{kg} / \mathrm{m} 2)$ & $30.6 \pm 4.2$ & $29.2 \pm 5.1$ & 0.13 \\
\hline Total Cholesterol (mg/dL) & $191.7 \pm 28.1$ & $176.6 \pm 35.0$ & 0.02 \\
\hline LDL cholesterol (mg/dL) & $115.0 \pm 28.3$ & $102.2 \pm 30.7$ & 0.03 \\
\hline Tryglicerides (mg/dL) & $128(96.0-161.5)$ & $113.5(82.5-159.5)$ & 0.57 \\
\hline HDL cholesterol (mg/dL) & $50.6 \pm 12.0$ & $50.1 \pm 11.5$ & 0.85 \\
\hline Lipid lowering drugs n (\%) & $32(52.5)$ & $35(79.5)$ & $<0.01$ \\
\hline Diabetics n (\%) & $32(52.5)$ & $35(79.5)$ & $<0.01$ \\
\hline Serum glucose (mg/dL) & $96(85.5-120.5)$ & $107(93.0-130.8)$ & 0.05 \\
\hline $\mathrm{HbA} 1 \mathrm{c}$ & $6.1(5.6-6.5)$ & $6.6(5.9-7.1)$ & 0.03 \\
\hline Antidiabetic drugs n (\%) & $31(50.8)$ & $31(70.5)$ & 0.05 \\
\hline Office SBP (mm Hg) & $127 \pm 14$ & $139 \pm 17$ & $<0.01$ \\
\hline Office DBP (mm Hg) & $77 \pm 9$ & $78 \pm 10$ & 0.59 \\
\hline Antihypertensive Drugs n (\%) & $50(82.0)$ & $36(81.8)$ & 0.98 \\
\hline CVR Framingham D'Agostino & $20.5 \pm 17.1$ & $32.0 \pm 20.8$ & $<0.01$ \\
\hline Serum creatinine $(\mathrm{mg} / \mathrm{dL})$ & $0.9(0.8-1.0)$ & $0.8(0.7-1.0)$ & 0.69 \\
\hline GFR with MDRD-IDMS (mL/min/1.73 m2) & $92.3 \pm 19.1$ & $87.6 \pm 20.0$ & 0.22 \\
\hline Albumin/creatinine (mg/g) & $2.97(0.00-8.25)$ & $2.31(0.00-14.03)$ & 0.93 \\
\hline Cornell VDP (mmms) & $1548.5 \pm 389.6$ & $1661.5 \pm 893.1$ & 0.38 \\
\hline Sokolow (mm) & $20.26 \pm 5.91$ & $19.72 \pm 7.04$ & 0.68 \\
\hline Ankle/brachial index & $1.14 \pm 0.11$ & $1.14 \pm 0.10$ & 0.95 \\
\hline Carotid IMT average mean (mm) & $0.74 \pm 0.10$ & $0.84 \pm 0.13$ & $<0.01$ \\
\hline cf-PWV (m/sec) & $8.63 \pm 2.63$ & $10.86 \pm 2.05$ & $<0.01$ \\
\hline ba-PWV (m/sec) & $13.18 \pm 1.41$ & $16.96 \pm 3.44$ & $<0.01$ \\
\hline Central Augmentation Index & $25.2 \pm 14.8$ & $30.0 \pm 10.1$ & 0.06 \\
\hline Peripheral augmentation index & $90(75-93)$ & $92.5(83-105)$ & 0.04 \\
\hline Arteriole-venule ratio & $0.73 \pm 0.11$ & $0.76 \pm 0.12$ & 0.29 \\
\hline
\end{tabular}

CAVI: Cardio-Ankle Vascular Index. LDL: Low Density Lipoprotein. HDL: High Density Lipoprotein. HbA1C: Glycosylated Hemoglobin. SBP: Systolic Blood Pressure. DBP: Diastolic Blood Pressure. CVR: CardioVascular Risk. GFR: Glomerular filtration rate. MDRD-IDMS: Modification of Diet in Renal Disease-Isotopic Dilution Mass Spectrometry. VDP: Voltage-Duration Product. IMT: Intima-Media Thickness. cf-PWV: carotid femoral Pulse Wave Velocity. ba-PWV: brachial ankle Pulse Wave Velocity.

with HbA1c $(r=0.30 \mathrm{p}<0.05)$ and systolic and diastolic blood pressure $(r=0.30$, and $r=0.26 \mathrm{p}<0.05)$, which was adjusted for age, sex, and the presence of antihypertensive, lipid-lowering, and antidiabetic drugs. It had a negative correlation with waist circumference and body mass index $(\mathrm{r}=-0.13$ and $\mathrm{r}=-0.24 ; \mathrm{p}<0.05)$.

In the multiple regression analysis, after adjustment for age, gender, cardiovascular risk, body mass index, and antihypertensive, antidiabetic, and lipid-lowering drugs, the CAVI as the independent variable showed a positive association with IMT $(\beta=0.29)$, cf-PWV $(\beta=0.83)$, ba-PWV $(\beta=2.12)$, CAIx $(\beta=3.42)$, and PAIx $(\beta=5.05)$ ( $\mathrm{p}<0.05$, all comparisons). We have found no correlation between CAVI and ABI or AVR (Table 4).

\section{Discussion}

The results of this study show that the CAVI is positively associated with IMT, cf-PWV, ba-PWV, CAIx, and PAIx, regardless of cardiovascular risk and the drug treatment used. Patients with cardiovascular TOD have higher values of CAVI. Likewise, the CAVI was positively correlated with age, HbA1c, SBP, and DBP, and it was negatively correlated with waist circumference and body mass index.

Similar to the data found in this work, the CAVI was positively related with carotid IMT, cf-PWV, and baPWV in type 2 diabetes mellitus patients [37]. These results suggest that CAVI is a useful clinical marker for evaluating atherosclerosis in subjects with increased 


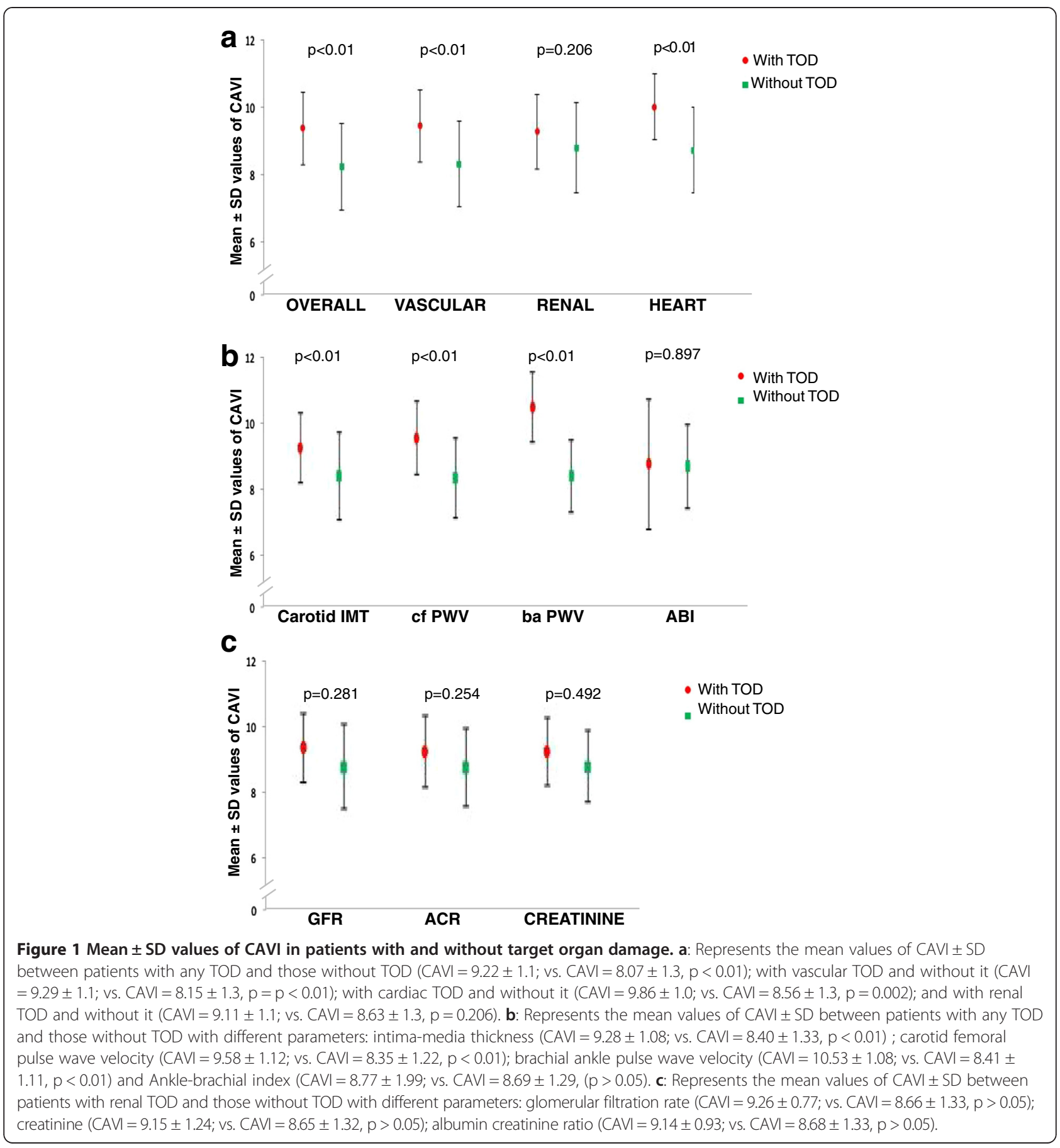

insulin resistance. Likewise, Kadota et al. [5] suggested the use of CAVI as a screening tool for atherosclerosis based on their findings from a general population study of 1014 adults showing strongly significant associations of CAVI scores with carotid intima-media thickness. Takaki et al. [25] compared the utility of these two parameters to detect arterial stiffness. Both CAVI and ba-PWV were significantly correlated with age and IMT. However, only CAVI was correlated with the parameters of left ventricular diastolic indices from echocardiography. Finally, only CAVI was significantly higher in the group with angina pectoris, and all parameters associated with atherosclerosis suggested that CAVI is superior to baPWV as a parameter of arterial stiffness.

Similarly we found an association between CAVI and ba-PWV or cf-PWV. The extent of atherosclerosis has been estimated using ba-PWV [6], ba-PWV are independently associated with the presence of coronary artery calcium 


\begin{tabular}{|c|c|c|c|}
\hline Dependent variable: & $\beta$ & $\mathrm{Cl} 95 \%$ & $\mathrm{p}$ value \\
\hline IMT average mean & 0.29 & 0.09 to 0.48 & $<0.01$ \\
\hline$A B I$ & 0.02 & -0.002 to 0.04 & 0.08 \\
\hline cf-PWV & 0.83 & 0.46 to 1.19 & $<0.01$ \\
\hline ba-PWV & 2.12 & 1.76 to 2.49 & $<0.01$ \\
\hline CAlx & 3.42 & 1.12 to 5.74 & $<0.01$ \\
\hline PAIx & 5.05 & 0.19 to 9.91 & 0.04 \\
\hline AVR & -0.01 & -0.03 to 0.01 & 0.38 \\
\hline
\end{tabular}

Dependent variable: IMT: Intima-Media Thickness of common carotid artery. ABI: Ankle Brachial Index. cf-PWV: carotid femoral Pulse Wave Velocity. ba-PWV: brachial ankle Pulse Wave Velocity. CAlx: Central Augmentation Index. PAlx: Peripheral Augmentation Index. AVR: ArterioVenous Ratio. Indepedent variable: CAVI: Cardio-Ankle Vascular Index. Adjusted by: Framingham D'Agostino cardiovascular risk score. Body mass index. Antihypertensive drugs. Lipid lowering drugs and antidiabetic drugs.

(CAC) [44], a marker of preclinical atherosclerosis [45], but this can be influenced by blood pressure, and it is not very reproducible. Because the CAVI is independent of BP, highly reproducible, easy to apply, and does not require special techniques, its potential as a novel parameter of atherosclerosis has recently become recognized [12]. Izuara et al. [38] suggested that CAVI reflects systemic arterial sclerosis, including carotid atherosclerosis and coronary atherosclerosis, and that CAVI might be more useful for discriminating the probability of coronary atherosclerosis than findings of carotid atherosclerosis by high-resolution ba-PWV $[29,46]$.

As far as we know, this is the first study that describes a positive association between the CAVI, the CAIx, and PAIx. Assessment of CAIx is a simple approach to quantify the role of wave reflection in determining an elevation of central blood pressure values $[31,39]$. Contrary to data published by Masugata et al. [47], who found a relationship between CAVI and the presence of left ventricule hypertrophy, this study found no relationship with either the left CAVI ventricule hypertrophy, renal TOD, the thickness of arteries and veins of the retina, or the ratio between the two.

In previous studies in Japanese population, has been described a negative association of CAVI with estimated glomerular filtration [48] and a positive correlation with the albumin creatinine ratio $[49,50]$. In our study, probably due to the low statistic power by the small sample size, we found no correlation with any of these parameters.

Consistent with previous studies, we found a positive correlation of CAVI with age, SBP, and DBP. Our study revealed that CAVI is highly correlated with age $(r=0.65)$, similar to the results reported by other authors for diabetic subjects [51,52] and for hypertensive diabetics $(\mathrm{r}=0.63)$ [24]. A study that examined 32627 healthy residents from
Japan showed that CAVI increases almost linearly with age from 20 to 70 years in males and females by 0.5 over 10 years [20].

The positive correlation between CAVI with SBP and DBP remains after adjusting for age, sex, and drug therapies used by patients. The results are consistent with those reported in diabetic patients [24]. However, in hypertensive patients, a correlation has only been found between CAVI and SBP, but not with DBP [20,28]. Some authors such as Nakamura et al. found no association of CAVI with blood pressure in patients with coronary disease [46]. These discrepancies suggest that the relationship of CAVI with the different components of blood pressure could be conditioned by previous disease presenting in the subjects analyzed.

Consistent with published results for patients with and without diabetes [52,53], the CAVI was positively correlated with HbA1c $(\mathrm{r}=0.298, \mathrm{p}<0.05)$. In summary, these results suggest that CAVI is a good tool to detect the presence of vascular TOD, carotid atherosclerosis, and arterial stiffness in Caucasian patients with increased insulin resistance, and they may be helpful in clinical practice for this patient group, completing the results published by Takata et al. in 2013 for an Asian population [54].

\section{Limitations}

The main limitation of this study was the source of the data for the cross-sectional study, which prevented us from establishing a temporal relationship between the CAVI and the different FRCV, TOD, and parameters that assess vascular function and structure during one week. Also, at the time of viewing these results, the subjects included in the study had multiple associated pathologies and were being treated with many drugs, which may have affected the CAVI values. We have tried to control this limitation by including the drugs most frequently used in the multiple regression analysis and in the correlation analysis as adjustment variables. Finally, the sample size of the individuals analyzed is not large.

\section{Conclusions}

The results of this study suggest that the CAVI is positively associated with IMT, cf-PWV, ba-PWV, CAIx, and PAIx, regardless of cardiovascular risk and the drug treatment used. Patients with cardiovascular TOD have higher values of CAVI. This relationship between CAIx, PAIx, and CAVI opens new lines of research, since they measure different aspects of arterial stiffness and could improve the treatment of cardiovascular diseases. 


\section{Abbreviations}

ABI: Ankle-brachial index; AV: Arteriolar-venular; AVR: Arteriolar-venular ratio; ba-PWV: Brachial ankle pulse wave velocity; BMI: Body mass index; BP: Blood pressure; CAVI: Cardio ankle vascular index; CAlx: Central augmentation index; cf-PW: Carotid femoral pulse wave velocity; Cornell VDP: Cornell voltage-duration product; DBP: Diastolic blood pressure; MDRD-IDMS: Modification of diet in renal disease-isotopic dilution mass spectrometry; GFR: Glomerular filtration rate; ICC: Intra-class correlation coefficient; IMT: Intima-media thickness; LVH: Left ventricular hypertrophy; PAlx: Peripheral augmentation index; PWV: Pulse wave velocity; TOD: Target organ damage; SBP: Systolic blood pressure; T2DM: Type 2 diabetes mellitus.

\section{Competing interests}

The authors declare that they have no competing interests.

\section{Authors' contributions}

MAGM devised the study, designed the protocol, participated in fund raising, interpreted the results, prepared the manuscript draft, and corrected the final version of the manuscript. JIRR and CAC participated in the study design, data collection, and manuscript review. MCPA performed all analytical methods, interpretation of results, and manuscript review. LGS, MGS, ERS and JAMF participated in the study design, interpretation of results, and manuscript review. LGO participated in the protocol design, fund raising, analysis of results, and final review of the manuscript. Finally, all authors reviewed and approved the final version of the manuscript.

\section{Acknowledgments}

We are grateful to all professionals participating in the LOD-DIABETES study. Coordinating Center: Manuel A Gomez-Marcos.

La Alamedilla health center (Castilla y Leon Health Service-SACYL, Salamanca, Spain) Cristina Agudo-Conde, Leticia Gomez-Sanchez, Marta Gomez-Sanchez, Carmen Castaño-Sanchez, Carmela Rodriguez-Martín, Benigna Sanchez-Salgado, Angela de Cabo Laso, Emiliano Rodriguez-Sanchez, Jose Angel Maderuelo-Fernandez, Emilio Ramos-Delgado, Carmen Patino-Alonso, Jose I Recio-Rodriguez, and Luis Garcia-Ortiz.

\section{Sources of funding}

The project has been funded by the Institute of Health Carlos III, (ISCiii) of the Ministry of Economy and Competitiveness (Spain) through the Network for Prevention and Health Promotion in Primary Care (redlAPP, RD12/0005), co-financed with European Union ERDF and the Autonomous Government of Castilla and León in 2009 and 2013 (GRS. 428/A/09; GRS 768/B/13), and the Intensification of Research Program.

\section{Author details}

'Primary Care Research Unit, the Alamedilla Health Center, Avda. Comuneros 27, 37003 Salamanca, Spain. ${ }^{2}$ Medicine Department, University of Salamanca, Salamanca, Spain. ${ }^{3}$ Statistics Department, University of Salamanca, Salamanca, Spain.

Received: 25 October 2014 Accepted: 28 December 2014 Published online: 16 January 2015

\section{References}

1. Won KB, Chang HJ, Kim HC, Jeon K, Lee H, Shin S, et al. Differential impact of metabolic syndrome on subclinical atherosclerosis according to the presence of diabetes. Cardiovasc Diabetol. 2013;12:41.

2. Barnett KN, Ogston SA, McMurdo ME, Morris AD, Evans JM. A 12-year follow-up study of all-cause and cardiovascular mortality among 10,532 people newly diagnosed with Type 2 diabetes in Tayside, Scotland. Diabet Med. 2010:27(10):1124-9.

3. Forti P, Pirazzoli GL, Maltoni B, Bianchi G, Magalotti D, Muscari A, et al. Metabolic syndrome and all-cause mortality in older men and women. Eur J Clin Invest. 2012;42(9):1000-9.

4. Fox CS. Cardiovascular disease risk factors, type 2 diabetes mellitus, and the Framingham Heart Study. Trends Cardiovasc Med. 2010;20(3):90-5.

5. Liang J, Wang Y, Li H, Liu X, Qiu Q, Qi L. Neck circumference and early stage atherosclerosis: the cardiometabolic risk in Chinese (CRC) study. Cardiovasc Diabetol. 2014;13(1):107.

6. Kelly PJ, Clarke PM, Hayes AJ, Gerdtham UG, Cederholm J, Nilsson P, et al. Predicting mortality in people with Type 2 diabetes mellitus after major complications: a study using Swedish National Diabetes Register data. Diabet Med. 2014;31(8):954-62.

7. Wong TY, Klein R, Sharrett AR, Duncan BB, Couper DJ, Tielsch JM, et al. Retinal arteriolar narrowing and risk of coronary heart disease in men and women. The Atherosclerosis Risk in Communities Study. JAMA. 2002;287(9):1153-9.

8. Gerstein HC, Mann JF, Yi Q, Zinman B, Dinneen SF, Hoogwerf B, et al. Albuminuria and risk of cardiovascular events, death, and heart failure in diabetic and nondiabetic individuals. JAMA. 2001;286(4):421-6.

9. Verdecchia P, Porcellati C, Reboldi G, Gattobigio R, Borgioni C, Pearson TA, et al. Left ventricular hypertrophy as an independent predictor of acute cerebrovascular events in essential hypertension. Circulation. 2001;104 (17):2039-44.

10. Isomaa B, Almgren $P$, Tuomi T, Forsen B, Lahti $K$, Nissen $M$, et al. Cardiovascular morbidity and mortality associated with the metabolic syndrome. Diabetes Care. 2001;24(4):683-9.

11. Mohan V, Pradeep R. Carotid intima-media thickness in type 2 diabetes mellitus. J Assoc Physicians India. 2012;60:9-10.

12. Resnick HE, Lindsay RS, McDermott MM, Devereux RB, Jones KL, Fabsitz RR, et al. Relationship of high and low ankle brachial index to all-cause and cardiovascular disease mortality: the Strong Heart Study. Circulation. 2004;109(6):733-9.

13. Mitchell GF, Hwang SJ, Vasan RS, Larson MG, Pencina MJ, Hamburg NM, et al. Arterial stiffness and cardiovascular events: the Framingham Heart Study. Circulation. 2010;121(4):505-11.

14. Maeda $Y$, Inoguchi T, Etoh E, Kodama Y, Sasaki S, Sonoda N, et al. Brachial-ankle pulse wave velocity predicts all-cause mortality and cardiovascular events in patients with diabetes: the Kyushu Prevention Study of Atherosclerosis. Diabetes Care. 2014;37(8):2383-90.

15. Yiu KH, Zhao CT, Chen Y, Siu CW, Chan YH, Lau KK, et al. Association of subclinical myocardial injury with arterial stiffness in patients with type 2 diabetes mellitus. Cardiovasc Diabetol. 2013;12:94.

16. Wu N, Cai X, Ye K, Li Y, He M, Zhao W, et al. Association between Brachial-Ankle pulse wave velocity and cardiac autonomic neuropathy in type 2 diabetes. Diabetol Metab Syndr. 2014;6(1):82.

17. Vlachopoulos C, Aznaouridis K, O'Rourke MF, Safar ME, Baou K, Stefanadis C. Prediction of cardiovascular events and all-cause mortality with central haemodynamics: a systematic review and meta-analysis. Eur Heart J. 2010;31(15):1865-71.

18. Munir S, Guilcher A, Kamalesh T, Clapp B, Redwood S, Marber M, et al. Peripheral augmentation index defines the relationship between central and peripheral pulse pressure. Hypertension. 2008;51(1):112-8.

19. Katakami N, Osonoi T, Takahara M, Saitou M, Matsuoka TA, Yamasaki Y, et al. Clinical utility of brachial-ankle pulse wave velocity in the prediction of cardiovascular events in diabetic patients. Cardiovasc Diabetol. 2014;13(1):128.

20. Shirai K, Hiruta N, Song M, Kurosu T, Suzuki J, Tomaru T, et al. Cardio-ankle vascular index (CAVI) as a novel indicator of arterial stiffness: theory, evidence and perspectives. J Atheroscler Thromb. 2011;18(11):924-38.

21. Takaki A, Ogawa H, Wakeyama T, Iwami T, Kimura M, Hadano Y, et al. Cardio-ankle vascular index is a new noninvasive parameter of arterial stiffness. Circ J. 2007;71(11):1710-4.

22. Kanamoto M, Matsumoto N, Shiga T, Kunimoto F, Saito S. Relationship between coronary artery stenosis and cardio-ankle vascular index (CAVI) in patients undergoing cardiovascular surgery. J Cardiovasc Dis Res. 2013:4(1):15-9.

23. Shirai K. Analysis of vascular function using the cardio-ankle vascular index (CAVI). Hypertens Res. 2011;34(6):684-5.

24. Wang H, Liu J, Zhao H, Fu X, Shang G, Zhou Y, et al. Arterial stiffness evaluation by cardio-ankle vascular index in hypertension and diabetes mellitus subjects. J Am Soc Hypertens. 2013;7(6):426-31.

25. Takaki A, Ogawa H, Wakeyama T, Iwami T, Kimura M, Hadano Y, et al. Cardio-ankle vascular index is superior to brachial-ankle pulse wave velocity as an index of arterial stiffness. Hypertens Res. 2008;31(7):1347-55.

26. Nagayama D, Endo K, Ohira M, Yamaguchi T, Ban N, Kawana H, et al. Effects of body weight reduction on cardio-ankle vascular index (CAVI). Obes Res Clin Pract. 2013;7(2):e139-45.

27. Izuhara M, Shioji K, Kadota S, Baba O, Takeuchi Y, Uegaito T, et al. Relationship of cardio-ankle vascular index (CAVI) to carotid and coronary arteriosclerosis. Circ J. 2008;72(11):1762-7.

28. Okura T, Watanabe S, Kurata M, Manabe S, Koresawa M, Irita J, et al. Relationship between cardio-ankle vascular index (CAVI) and carotid 
atherosclerosis in patients with essential hypertension. Hypertens Res. 2007:30(4):335-40.

29. Nakamura K, Tomaru T, Yamamura S, Miyashita Y, Shirai K, Noike H. Cardio-ankle vascular index is a candidate predictor of coronary atherosclerosis. Circ J. 2008;72(4):598-604.

30. Namekata T, Suzuki K, Ishizuka N, Shirai K. Establishing baseline criteria of cardio-ankle vascular index as a new indicator of arteriosclerosis: a cross-sectional study. BMC Cardiovasc Disord. 2011;11:51.

31. Gomez-Marcos MA, Recio-Rodriguez Jl, Rodriguez-Sanchez E, Castano-Sanchez Y, de Cabo-Laso A, Sanchez-Salgado B, et al. Central blood pressure and pulse wave velocity: relationship to target organ damage and cardiovascular morbidity-mortality in diabetic patients or metabolic syndrome. An observational prospective study. LOD-DIABETES study protocol. BMC Public Health. 2010;10:143

32. American Diabetes Association. Diagnosis and classification of diabetes mellitus. Diabetes Care. 2010;33 Suppl 1:S62-9.

33. Grundy SM, Cleeman JI, Daniels SR, Donato KA, Eckel RH, Franklin BA, et al. Diagnosis and management of the metabolic syndrome: an American Heart Association/National Heart, Lung, and Blood Institute Scientific Statement. Circulation. 2005;112(17):2735-52.

34. World Medical Association. World Medical Association Declaration of Helsinki: ethical principles for medical research involving human subjects. JAMA. 2013;310(20):2191-4

35. Mancia G, Fagard R, Narkiewicz K, Redon J, Zanchetti A, Bohm M, et al. 2013 ESH/ESC Guidelines for the management of arterial hypertension: the Task Force for the management of arterial hypertension of the European Society of Hypertension (ESH) and of the European Society of Cardiology (ESC). J Hypertens. 2013;31(7):1281-357.

36. Hu H, Cui H, Han W, Ye L, Qiu W, Yang H, et al. A cutoff point for arterial stiffness using the cardio-ankle vascular index based on carotid arteriosclerosis. Hypertens Res. 2013;36(4):334-41.

37. Kawai T, Ohishi M, Onishi M, Ito N, Takeya Y, Maekawa Y, et al. Cut-off value of brachial-ankle pulse wave velocity to predict cardiovascular disease in hypertensive patients: a cohort study. J Atheroscler Thromb. 2013;20(4):391-400.

38. Gomez-Marcos MA, Recio-Rodriguez JI, Patino-Alonso MC, Agudo-Conde C Gomez-Sanchez L, Gomez-Sanchez M, et al. Protocol for measuring carotid intima-media thickness that best correlates with cardiovascular risk and target organ damage. Am J Hypertens. 2012;25(9):955-61.

39. Wong TY, Duncan BB, Golden SH, Klein R, Couper DJ, Klein BE, et al. Associations between the metabolic syndrome and retinal microvascular signs: the Atherosclerosis Risk In Communities study. Invest Ophthalmol Vis Sci. 2004;45(9):2949-54.

40. Garcia-Ortiz L, Recio-Rodriguez Jl, Parra-Sanchez J, Gonzalez Elena LJ, Patino-Alonso MC, Agudo-Conde C, et al. A new tool to assess retinal vessel caliber. Reliability and validity of measures and their relationship with cardiovascular risk. J Hypertens. 2012;30(4):770-7.

41. Levey AS, Bosch JP, Lewis JB, Greene T, Rogers N, Roth D. A more accurate method to estimate glomerular filtration rate from serum creatinine: a new prediction equation. Modification of Diet in Renal Disease Study Group. Ann Intern Med. 1999;130(6):461-70.

42. Mancia G, De Backer G, Dominiczak A, Cifkova R, Fagard R, Germano G, et al. 2007 Guidelines for the Management of Arterial Hypertension: The Task Force for the Management of Arterial Hypertension of the European Society of Hypertension (ESH) and of the European Society of Cardiology (ESC). J Hypertens. 2007;25(6):1105-87.

43. D'Agostino Sr RB, Vasan RS, Pencina MJ, Wolf PA, Cobain M, Massaro JM, et al. General cardiovascular risk profile for use in primary care: the Framingham Heart Study. Circulation. 2008;117(6):743-53.

44. Sung KC, Lim YH, Park S, Kang SM, Park JB, Kim BJ, et al. Arterial stiffness, fatty liver and the presence of coronary artery calcium in a large population cohort. Cardiovasc Diabetol. 2013;12(1):162.

45. Yeboah J, Erbel R, Delaney JC, Nance R, Guo M, Bertoni AG, et al. Development of a new diabetes risk prediction tool for incident coronary heart disease events: the Multi-Ethnic Study of Atherosclerosis and the Heinz Nixdorf Recall Study. Atherosclerosis. 2014;236(2):411-7.

46. Horinaka S, Yabe A, Yagi H, Ishimura K, Hara H, lemua T, et al. Comparison of atherosclerotic indicators between cardio ankle vascular index and brachial ankle pulse wave velocity. Angiology. 2009;60(4):468-76.
47. Masugata H, Senda S, Inukai M, Himoto T, Hosomi N, Murao K, et al. Association between left ventricular hypertrophy and changes in arterial stiffness during hypertensive treatment. Clin Exp Hypertens. 2014;36(4):258-62

48. Kubozono T, Miyata M, Ueyama K, Nagaki A, Hamasaki S, Kusano K, et al. Association between arterial stiffness and estimated glomerular filtration rate in the Japanese general population. J Atheroscler Thromb. 2009;16(6):840-5.

49. Ito R, Yamakage H, Kotani K, Wada H, Otani S, Yonezawa K, Saito M, Nagaoka T, Toyonaga T, Tanaka T, Yamada T, Ota I, Oishi M, Miyanaga F, Shimatsu A, Satoh-Asahara N. Comparison of cystatin C- and creatinine-based estimated glomerular filtration rate to predict coronary heart disease risk in Japanese patients with obesity and diabetes. Endocr J. 2014. [Epub ahead of print] PubMed PMID: 25399862.

50. Nakamura K, lizuka T, Takahashi M, Shimizu K, Mikamo H, Nakagami T, et al. Association between cardio-ankle vascular index and serum cystatin C levels in patients with cardiovascular risk factor. J Atheroscler Thromb. 2009;16(4):371-9.

51. Tian G, Wei W, Zhang W, Zhang L, You H, Liu W, et al. Increasing age associated with elevated cardio-ankle vascular index scores in patients with type 2 diabetes mellitus. J Int Med Res. 2013;41(2):435-44.

52. Ibata J, Sasaki H, Kakimoto T, Matsuno S, Nakatani M, Kobayashi M, et al. Cardio-ankle vascular index measures arterial wall stiffness independent of blood pressure. Diabetes Res Clin Pract. 2008:80(2):265-70.

53. Huang $C L$, Chen MF, Jeng JS, Lin LY, Wang WL, Feng MH, et al. Postchallenge hyperglycaemic spike associate with arterial stiffness. Int J Clin Pract. 2007;61(3):397-402.

54. Takata M, Shimakura A. [Cardio-ankle vascular index (CAVI) and cardiovascular disease]. Rinsho Byori. 2013;61(10):924-33.

\section{Submit your next manuscript to BioMed Central and take full advantage of:}

- Convenient online submission

- Thorough peer review

- No space constraints or color figure charges

- Immediate publication on acceptance

- Inclusion in PubMed, CAS, Scopus and Google Scholar

- Research which is freely available for redistribution 